\title{
Composição do suco de uva caseiro de diferentes cultivares
}

\author{
Composition of homemade grape juice from different varieties
}

\author{
Luiz Antenor Rizzon ${ }^{1}$ Marcos Link ${ }^{2}$
}

\section{RESUMO}

Um volume considerável de uva do grupo das americanas da Serra Gaúcha é destinado para a produção de suco de uva caseiro. O objetivo do presente trabalho foi avaliar o efeito das cultivares Isabel, Bordô (Ives) e Concord de Vitis Iabrusca e Cabernet Sauvignon de Vitis vinifera, na composição do suco de uva, elaborado na Embrapa Uva e Vinho na safra de 2003. Os sucos foram avaliados quanto às análises clássicas: densidade, ${ }^{\circ} \mathrm{Brix}$, acidez total, acidez volátil, $\mathrm{pH}$ e relação ${ }^{\circ} \mathrm{Brix} /$ acidez total, efetuadas através de métodos físico-químicos. Os compostos voláteis etanol, metanol e aldeído acético foram determinados através da cromatografia gasosa. Os elementos minerais $\mathrm{Ca}, \mathrm{Mg}, \mathrm{Mn}, \mathrm{Fe}, \mathrm{Cu}$ e $\mathrm{Zn}$ foram analisados por absorção atômica, enquanto que o $\mathrm{K}, \mathrm{Na}$ e $\mathrm{Rb}$, por emissão de chama. $O P$ foi determinado por colorimetria. Os resultados evidenciaram variabilidade entre os sucos das diferentes cultivares. O suco de Cabernet Sauvignon diferenciou-se dos demais pelos menores teores de metanol e etanol e pelos maiores de acidez volátil e Fe. Os sucos da uva Bordô e Concord apresentaram menor teor de acidez total e de Mn.

Palavras-chave: uva, processamento, caracterização.

\section{ABSTRACT}

A great amount of American grapes is employed to produce homemade juice in the Serra Gaúcha Region. The purpose of this work was to evaluated the effects of Vitis labrusca cultivars (Isabel, Bordô (Ives), Concord) and a Vitis vinifera cultivar (Cabernet Sauvignon), in the juice composition. The juice was prepared at Embrapa in Bento Gonçalves, RS, in the 2003 vintage. The juices had been evaluated as classic analysis: density, ${ }^{\circ}$ Brix, total and volatile acidity, $\mathrm{pH},{ }^{\circ}$ Brix total acidity ratio, made by the physical-chemical methods. The volatile components ethanol, methanol and acetaldehyde were determined by gas chromatography. The mineral elements Ca, $\mathrm{Mg}, \mathrm{Mn}, \mathrm{Fe}, \mathrm{Cu}$ and $\mathrm{Zn}$ had been analysed by atomic absorption when the K, Na and Rb by flame emission. The results showed variability among juices from different grape varieties. Cabernet Sauvignon juice dintinguished by the smaller methanol and ethanol quality and the highest concentration of volatile acidity and Fe. The Bordô and Concord have shown less level of total acidity and $\mathrm{Mn}$.

Key words: grape, processing, characterization.

Um volume considerável de uva do grupo das americanas da Serra Gaúcha é destinado para a elaboração de suco de uva caseiro que utiliza um equipamento simples, denominado panela extratora. $\mathrm{O}$ suco de uva é engarrafado à quente, em uma temperatura suficiente para garantir a estabilidade biológica e a conservação sem aditivos químicos (RIZZON et al., 1998).

Quanto à composição química, o suco de uva possui teor elevado de açúcar, glicose e frutose, considerado, por isso, um alimento energético. A acidez do suco é devido à presença dos ácidos tartárico, málico e cítrico. Esses ácidos orgânicos lhe conferem um $\mathrm{pH}$ baixo, garantindo um equilíbrio entre os gostos

\footnotetext{
${ }^{1}$ Embrapa Uva e Vinho, CP 130, 95700-000, Bento Gonçalves, RS, Brasil. E-mail: rizzon@cnpuv.embrapa.br. Autor para correspondência.

${ }^{2}$ Curso de Agronomia, Centro Federal de Educação Tecnológica do Paraná (CEFET-PR), 85660-000, Pato Branco, PR, Brasil. Email:marcos.link@bol.com.br
} 
doce e ácido. Entre os elementos minerais, destacamse o elevado teor de K e o baixo teor de Na (RIZZON \& MIELE, 1995). Além desses minerais, encontram-se também no suco de uva o $\mathrm{Ca}$, o $\mathrm{Mg}$ e o $\mathrm{P}$ em concentrações mais elevadas. O Mn, o Fe, o Cu, o Zn, o Li e o Rb estão presentes como microelementos. Encontram-se também compostos fenólicos responsáveis pela cor, adstringência e estrutura, sendo as antocianinas, os taninos e os ácidos fenólicos, os mais importantes. Os compostos nitrogenados do suco de uva são constituídos por aminoácidos, polipeptídeos e proteínas (MIELE et al.,1990). Os compostos voláteis são responsáveis pelo aroma do suco de uva. Alguns desses compostos originaram-se na própria uva, outros do processo fermentativo, como no caso do etanol e aldeído acético. O metanol originase da hidrólise das pectinas no contato da película da uva esmagada com o mosto (RIBÉREAU-GAYON, et al., 1998).

O suco de uva da Serra Gaúcha é elaborado com uva das cultivares do grupo das americanas, especialmente com a Isabel, a Bordô e a Concord (ZANUS, 1991). No entanto, essas uvas possuem teor de pectina mais elevado em comparação com as cultivares de Vitis vinifera (RIBÉREAU-GAYON et al., 1998).

O objetivo foi estudar a influência da cultivar na composição do suco de uva.

O trabalho foi realizado na Embrapa Uva e Vinho em Bento Gonçalves-RS, na safra de 2003. Foram avaliados os sucos das cultivares Isabel, Bordô e Concord (Vitis labrusca) e Cabernet Sauvignon (Vitis vinifera). Os sucos foram elaborados pelo processo caseiro com o equipamento conhecido por panela extratora. O delineamento experimental utilizado foi o de blocos casualizados, considerando as quatro cultivares como tratamentos e as duas extrações com $18 \mathrm{~kg}$ como repetições, originando doze amostras de suco de 500mL cada uma, sendo seis utilizadas para a análise. Os resultados foram submetidos à análise de variância e ao teste de Tukey para comparação das médias à 5\% de probabilidade de erro.

$\mathrm{O}{ }^{\circ}$ Brix foi obtido através da leitura em um refratômetro de bancada com correção automática de temperatura. A densidade foi determinada com um densímetro eletrônico. A acidez total foi analisada através de método titulométrico, utilizando o azul de bromotimol como indicador. A acidez volátil foi avaliada através do arraste de vapor com o aparelho Cazenave Ferré. O pH foi determinado com potenciômetro aferido com soluções de pH 3,0 e 4,0 (AMATI et al., 1975). Os compostos voláteis - metanol e etanol - foram determinados por cromatografia gasosa (BERTRAND,
1975). Os minerais - Ca, Mg, Mn, Fe, Cu e Zn - foram analisados por absorção atômica, enquanto o K, o Na e Rb por emissão de chama (PERKIN-ELMER, 2000). O $\mathrm{P}$ foi determinado por colorimetria (TEDESCO et al., 1995).

Os resultados não evidenciaram diferenças significativas na densidade, ${ }^{\circ}$ Brix, aldeído acético, K, Na, Mg, Zn e Rb (Tabela 1). De modo geral, observaramse valores baixos do ${ }^{\circ}$ Brix, devido ao efeito da diluição do vapor da água, utilizada no aquecimento e na extração da matéria corante da uva, em decorrência do tipo de equipamento utilizado. Os valores ficaram abaixo de 14º̉ix, mínimo estabelecido pela legislação brasileira para suco de uva (BRASIL, 1974).

Detectaram-se valores mais baixos de acidez total para os sucos de uva das cultivares Bordô e Concord e mais elevados para a Isabel e Cabernet Sauvignon, devido a características varietais. O suco da cultivar Isabel, elaborado na Serra Gaúcha, tem apresentado acidez elevada, devido ao teor de ácidos fixos presentes na película e liberados ao suco no processo de elaboração (RIZZON et al., 1998), comportamento semelhante observado na vinificação. Observou-se teor mais elevado de acidez volátil no suco de uva de Cabernet Sauvignon, provavelmente devido ao estado sanitário da uva. No entanto, os valores são baixos e se enquadram nos limites estabelecidos pela legislação brasileira, que é de 8,0meq $\mathrm{L}^{-1}$. A relação ${ }^{\circ} \mathrm{Brix} / \mathrm{acidez}$ total representa o equilíbrio entre o gosto doce e ácido do suco de uva, portanto, um indicativo de qualidade de suco de uva (PEZZI \& FENOCCHIO, 1976). A legislação brasileira estabelece os limites dessa relação entre 15 e 45 . Os valores mais elevados representam sucos de uva menos ácidos. O valor mais elevado foi detectado no suco de uva Concord, devido à acidez mais baixa. Constataram-se teores mais baixos dos compostos voláteis, etanol e metanol no suco de uva da cultivar Cabernet Sauvignon. O teor mais baixo de etanol no suco de Cabernet Sauvignon foi devido à não ocorrência do processo fermentativo. Os níveis de etanol detectados foram bem inferiores ao limite de 1\% estabelecido pela legislação brasileira (BRASIL, 1974). O metanol encontrado no suco de uva provém da hidrólise das pectinas no período em que a película permanece em contato com o mosto, para extrair os compostos fenólicos da cor. A concentração baixa de metanol detectada no suco de Cabernet Sauvignon é conseqüência do menor teor de pectina, presente nas cultivares de Vitis vinifera em relação aquelas do grupo das americanas da espécie de Vitis labrusca (RIBÉREAU-GAYON et al., 1998). 
Tabela 1 - Composição do suco de uva das cultivares Isabel, Bordô, Concord e Cabernet Sauvignon - Safra 2003.

\begin{tabular}{|c|c|c|c|c|c|c|c|}
\hline \multirow{2}{*}{ Variável } & \multicolumn{4}{|c|}{ Cultivar } & \multirow[b]{2}{*}{ Média de cultivares } & \multirow[b]{2}{*}{ CV(\%) } & \multirow[b]{2}{*}{ Prob. $>$ F } \\
\hline & Isabel & Bordô & Concord & $\begin{array}{l}\text { Cabernet } \\
\text { Sauvignon }\end{array}$ & & & \\
\hline Densidade a $20^{\circ} \mathrm{C}\left(\mathrm{g} \mathrm{mL}^{-1}\right)$ & $1,055^{\mathrm{a} *}$ & $1,052 \mathrm{a}$ & $1,055 a$ & $1,058 \mathrm{a}$ & 1,055 & 0,2 & 0,08022 \\
\hline Sólidos solúveis totais ( $\left.{ }^{\circ} \mathrm{Brix}\right)$ & $12,9 a$ & $12,2 \mathrm{a}$ & $12,9 a$ & $13,1 \mathrm{a}$ & 12,8 & 2,6 & 0,16313 \\
\hline Acidez total (meq L ${ }^{-1}$ ) & $104,5 a$ & $89,1 \mathrm{~b}$ & $79,8 b$ & $110,9 a$ & 93,6 & 2,7 & 0,00356 \\
\hline Acidez volátil (meq L ${ }^{-1}$ ) & $2,0 \mathrm{~b}$ & $1,7 \mathrm{~b}$ & $2,0 \mathrm{~b}$ & $3,0 \mathrm{a}$ & 2,2 & 8,1 & 0,00953 \\
\hline $\mathrm{pH}$ & $3,25 c$ & $3,44 a$ & $3,37 b$ & $3,40 \mathrm{ab}$ & 3,37 & 0,4 & 0,00182 \\
\hline Relação ${ }^{\circ}$ Brix/acidez total & $16,5 b$ & $18,3 b$ & $21,5 a$ & $18,0 \mathrm{~b}$ & 18,6 & 2,9 & 0,00527 \\
\hline Etanol $\left(\mathrm{mg} / \mathrm{L}^{-1}\right)$ & $673 a$ & $729 a$ & $783 a$ & $211 b$ & 599 & 10,8 & 0,00465 \\
\hline Metanol (mg L $\left.{ }^{-1}\right)$ & $128,6 a$ & $135,3 a$ & $135,1 \mathrm{a}$ & $56,5 b$ & 113,9 & 17,0 & 0,03898 \\
\hline Aldeído acético (mg L ${ }^{-1}$ ) & $24,1 \mathrm{a}$ & $24,4 a$ & $25,7 a$ & $29,4 a$ & 25,9 & 13,9 & 0,50167 \\
\hline $\mathrm{K}\left(\mathrm{mg} \mathrm{L}^{-1}\right)$ & $1445 a$ & $1764 a$ & $1372 \mathrm{a}$ & $1538 a$ & 1530 & 6,5 & 0,06095 \\
\hline $\mathrm{Na}\left(\mathrm{mg} \mathrm{L}^{-1}\right)$ & $2,6 a$ & $1,8 \mathrm{a}$ & $4,6 a$ & 3,9a & 3,2 & 31,1 & 0,14128 \\
\hline $\mathrm{Ca}\left(\mathrm{mg} \mathrm{L}^{-1}\right)$ & $67,4 \mathrm{ab}$ & $88,9 a$ & $51,8 b$ & $67,4 \mathrm{ab}$ & 68,9 & 10,5 & 0,03209 \\
\hline $\operatorname{Mg}\left(\mathrm{mg} \mathrm{L}^{-1}\right)$ & $70,1 \mathrm{a}$ & $62,3 a$ & 66,3a & 59,3а & 64,5 & 4,8 & 0,08800 \\
\hline $\operatorname{Mn}\left(\mathrm{mg} \mathrm{L}^{-1}\right)$ & $1,0 \mathrm{a}$ & $0,2 \mathrm{~b}$ & $0,5 b$ & $0,9 a$ & 0,64 & 16,6 & 0,00663 \\
\hline $\mathrm{Cu}\left(\mathrm{mg} \mathrm{L}^{-1}\right)$ & $1,3 c$ & 3,6ab & $2,5 b c$ & $4,5 \mathrm{a}$ & 3,0 & 15,9 & 0,01234 \\
\hline $\mathrm{Fe}\left(\mathrm{mg} \mathrm{L}^{-1}\right)$ & $0,8 b$ & $0,7 \mathrm{~b}$ & $0,5 \mathrm{c}$ & $1,1 \mathrm{a}$ & 0,79 & 4,5 & 0,00151 \\
\hline $\mathrm{Zn}\left(\mathrm{mg} \mathrm{L}^{-1}\right)$ & $0,25 a$ & $0,15 a$ & $0,20 a$ & $0,35 a$ & 0,24 & 25,8 & 0,11213 \\
\hline $\mathrm{Rb}\left(\mathrm{mg} \mathrm{L}^{-1}\right)$ & $4,1 \mathrm{a}$ & $3,0 \mathrm{a}$ & $3,0 \mathrm{a}$ & $4,2 \mathrm{a}$ & 3,57 & 15,1 & 0,15504 \\
\hline $\mathrm{P}\left(\mathrm{mg} \mathrm{L}^{-1}\right)$ & 72,0ab & $96,5 a$ & $66,8 b$ & $69,0 \mathrm{~b}$ & 76,1 & 7,1 & 0,02648 \\
\hline
\end{tabular}

*Valores seguidos por letras distintas na linha diferem entre si pelo teste de Tukey a 5\% de probabilidade de erro.

O teor mais elevado de Ca no suco de Bordô e mais baixo no de Concord, deve-se provavelmente à maior presença do elemento na película da uva e proveniente dos tratamentos fitossanitários. O teor mais elevado de Mn nos sucos de Isabel e Cabernet Sauvignon e mais baixo no suco de Bordô e Concord, possivelmente seja uma característica varietal, relacionada à formação das sementes, visto que o elemento está presente em maior quantidade nas mesmas. Observou-se teor mais elevado de Cu no suco de Cabernet Sauvignon, e mais baixo no Isabel, devido à aplicação da calda bordalesa na uva. A maior proporção de película devido ao menor tamanho da baga, na cultivar Cabernet Sauvignon pode interferir no teor de cobre no suco dessa cultivar. Em relação ao Fe, mesmo que tenha sido detectada variação em relação às diferentes cultivares, os teores são baixos e as diferenças parecem estar relacionadas com a cultivar. Detectou-se teor mais elevado de $\mathrm{P}$ no suco de uva Bordô e valores mais baixos nos sucos de Concord e Cabernet Sauvignon. A variação do teor de P está relacionado com o grau de maturação da uva e com a cultivar.

O suco de uva de Cabernet Sauvignon apresentou teor mais baixo dos compostos voláteis metanol e etanol e mais elevado de acidez volátil e de Fe que os demais sucos. Os sucos das cultivares Bordô e Concord apresentaram menor teor de acidez total, aspecto importante para participar de cortes como o de Isabel, para melhorar as características.

\section{REFERÊNCIAS}

AMATI, A. et al. Il suco d'uva: caractteristiche e tecnologia de produzione. Vignevini, Bologna, v.2, n.6, p.11-16, 1975.

BERTRAND, A. Recherches sur l'analyse des vins par chromatographie en phase gazeuse. 1975. 291f. Tese (Doutorado em Enologia) - Université de Bordeaux II.

BRASIL. Ministério da Agricultura. Secretaria Nacional de Defesa Agropecuária. Secretaria de Inspeção de Produtos Vegetais. Complementação de padrões de identidade e qualidade para suco, refresco e refrigerante de uva. Brasília, 1974. 29p.

MIELE, A. et al. Free amino acids in Brazilian grape juices. Rivista di Viticoltura e di Enologia, Conegliano, v.43, n.4, p.15-21, 1990.

PERKIN-ELMER. Analytical methods for atomic absorption spectrometry. Singapura: Perkin-Elmer Instruments, 2000. 300p. 
PEZZI, G.M.; FENOCCHIO, P. Estudo analítico dos sucos de uva comerciais. Pesquisa Agropecuária Brasileira, Brasília, v.11, n.12, p.11-13, 1976.

RIBÉREAU-GAYON, P. et al. Traité d'oenologie. 2. Chimie du vin stabilisation et traitements. Paris: Dunod, 1998. 519p.

RIZZON, L.A.; MIELE, A. Características analíticas de sucos de uva elaborados no Rio Grande do Sul. Boletim Sociedade Brasileira de Ciência e Tecnologia de Alimentos, Campinas, v.29, n.2, p.129-133, 1995.
RIZZON, L.A. et al. Elaboração de suco de uva na propriedade vitícola. Bento Gonçalves: Embrapa Uva e Vinho, 1998. 24p. (Embrapa Uva e Vinho. Documentos, 21).

TEDESCO, M. et al. Análise de solo, plantas e outros materiais. Porto Alegre: Departamentos de Solos, Faculdade de Agronomia, UFRGS, 1995. 174p. (Boletim Técnico, 5).

ZANUS, M.C. Efeito da maturação sobre a composição do mosto e qualidade do suco de uva. 1991. 177f. Dissertação (Mestrado em Fitotecnia) - UFRGS. 